\title{
Parotid carcinoma following chronic lymphocytic inflammation with pontine perivascular enhancement responsive to steroids: a case report
}

Yilun Deng ${ }^{1}$, Bi Zhao ${ }^{1}$, Bing Wei ${ }^{2}$, Shihong Zhang ${ }^{1 *}$ and Ming Liu ${ }^{1 *}$

\begin{abstract}
Background: Chronic lymphocytic inflammation with pontine perivascular enhancement responsive to steroids (CLIPPERS) is an inflammatory disorder with unclear causes. Paraneoplastic etiology may be a cause. We report a case of CLIPPERS with parotid carcinoma.

Case presentation: A 54-year-old man with a history of lymphoma was hospitalized with a pontocerebellar syndrome. Brain MRI revealed that the pons and cerebellum were "peppered" with punctate and curvilinear enhancement lesions that supported the diagnosis of CLIPPERS. The relapse of lymphoma was excluded by a further cerebellum biopsy revealing predominantly CD3+ T cells in white matter. The patient was relieved after pulse therapy with intravenous methylprednisolone and a large dose of corticosteroids, but he complained of a worsening gait problem when corticosteroids were tapered to a lower dose. Although the clinical symptoms gradually improved again by increasing the dosage of corticosteroids with Azathioprine, the patient still had a slight unsteady gait during follow-up. At the 7-month follow-up, a parotid mass was detected by MRI and was verified as carcinoma by biopsy. After resection of parotid carcinoma, the residual symptoms and previous MRI lesions disappeared, and no relapse occurred.
\end{abstract}

Conclusions: CLIPPERS may not be a distinct nosologic entity but an overlapping diagnosis with other diseases. Some cases of CLIPPERS might be a subtype of paraneoplastic neurological syndromes (PNS) due to the similar mechanism of antibody-mediated encephalitis. Tumor screening and serum paraneoplastic autoantibody tests are recommended for patients with CLIPPERS, especially for those who relapse when corticosteroids treatment is stopped or tapered.

Keywords: CLIPPERS, PNS, Parotid carcinoma

\footnotetext{
*Correspondence: zsh9@hotmail.com; wyplmh@hotmail.com

'Department of Neurology, West China Hospital, Sichuan University, Chengdu, Sichuan, China

Full list of author information is available at the end of the article
}

(C) The Author(s). 2021 Open Access This article is licensed under a Creative Commons Attribution 4.0 International License, which permits use, sharing, adaptation, distribution and reproduction in any medium or format, as long as you give appropriate credit to the original author(s) and the source, provide a link to the Creative Commons licence, and indicate if changes were made. The images or other third party material in this article are included in the article's Creative Commons licence, unless indicated otherwise in a credit line to the material. If material is not included in the article's Creative Commons licence and your intended use is not permitted by statutory regulation or exceeds the permitted use, you will need to obtain permission directly from the copyright holder. To view a copy of this licence, visit http://creativecommons.org/licenses/by/4.0/ The Creative Commons Public Domain Dedication waiver (http://creativecommons.org/publicdomain/zero/1.0/) applies to the data made available in this article, unless otherwise stated in a credit line to the data. 


\section{Background}

Chronic lymphocytic inflammation with pontine perivascular enhancement responsive to steroids (CLIPPERS) is a brainstem-predominant inflammatory syndrome with punctate and curvilinear enhancing lesions on brain MRI initially defined by Pittock [1]. These lesions are mainly distributed mainly in the pons and cerebellum and can extend, in a lesser degree, to the medulla, midbrain, brachium pontis and cortical-subcortical regions [2].

The pathogenesis of CLIPPERS remains unknown. The predominance of T-cells on histopathology and responsiveness to steroids treatment support an immune-mediated or other inflammatory causes; moreover, very few cases have reported on the role of paraneoplastic etiology during the disease cascade [2-4]. Here, we present the first case of CLIPPERS with parotid carcinoma, a combination that has not previously been reported in the literature.

\section{Case presentation}

In July 2017, a 54-year-old Chinese male with progressive gait disturbance, dysarthria and intermittent diplopia for more than 2 months was admitted. He had a history of cured Hodgkin's lymphoma 9 years prior. The neurological examination revealed horizontal nystagmus, mild dysarthria, ataxia gait and impaired coordinated movements of limbs. MRI T2-weighted and fluid attenuated inversion recovery sequence images revealed multiple patchy hyperintense lesions bilaterally scattered in the pons, cerebellum, midbrain and middle cerebellar peduncle with nodular gadolinium enhancing (Fig. 1. A1, A2). Positron emission tomography-CT had been performed in clinic before admission revealed abnormal accumulation of fluorodeoxyglucose in the right cerebellum, which was concerning for a recurred lymphoma. In addition, lumbar puncture was performed in another hospital before admission which only demonstrated a mildly elevated protein concentration $(84 \mathrm{mg} / \mathrm{dl})$ and an unremarkable cytology. Cerebellar biopsy was performed and it demonstrated parenchymal and perivascular lymphocytic inflammatory infiltrate in the white matter (Supplementary information. Figure S1. A). Serum serological tests for syphilis and human immunodeficiency virus were negative. Except for a mildly elevated antinuclear antibodies titer (1:100), the other autoimmune antibody tests were negative. Cerebrospinal fluid (CSF) examination revealed a mildly elevated protein concentration $(77 \mathrm{mg} / \mathrm{dl})$. Cytology, flow cytometry, immunoglobulin $\mathrm{G}$ index and culture of the CSF were unremarkable. Given the lack of evidence for lymphoma, a possible autoinflammatory etiology was considered. A 5-day course of intravenous immunoglobulin ( $400 \mathrm{mg} /$ day per kilo of weight) was given and the patient was discharged.

One month later, the patient was readmitted with no clinical and radiological improvement. This time,

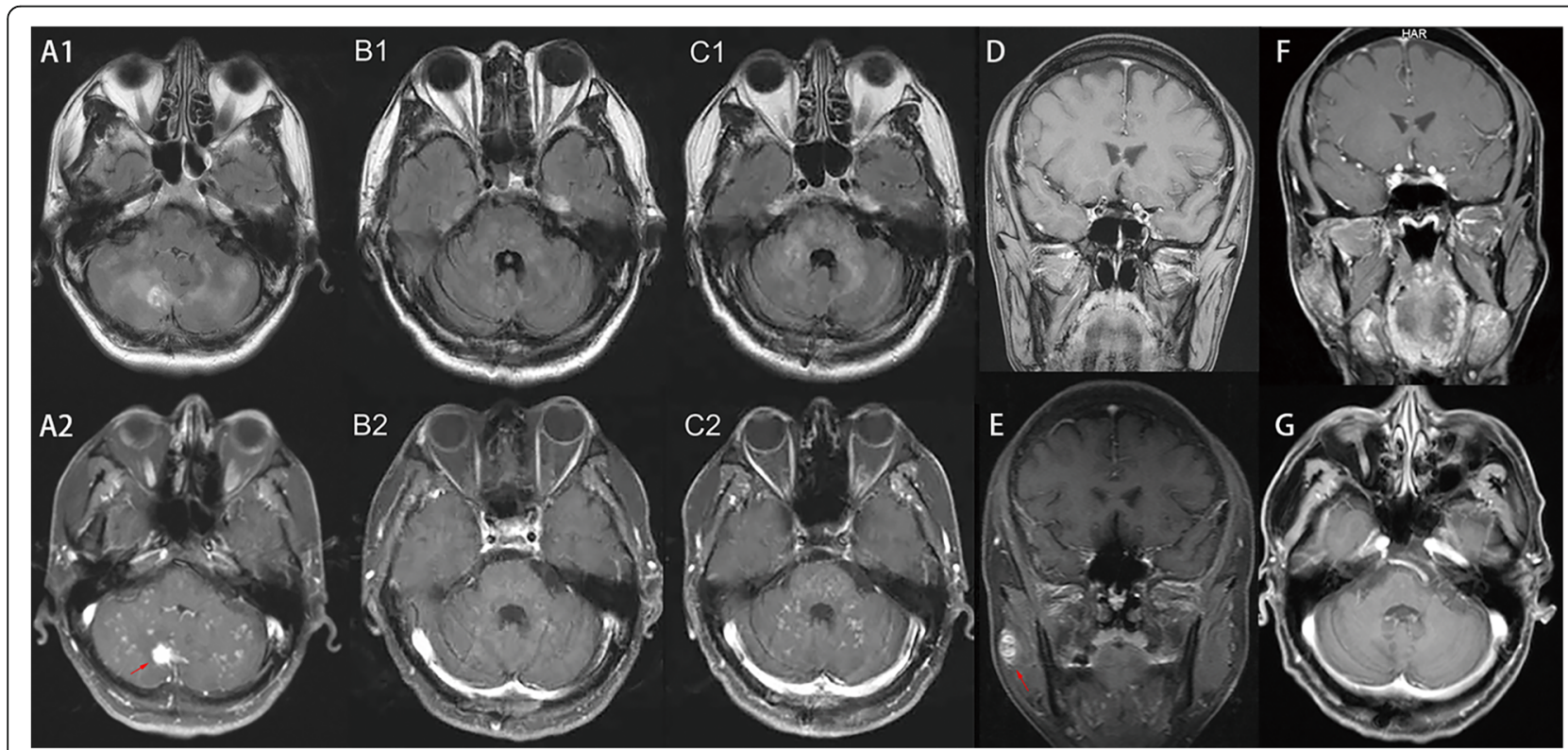

Fig. 1 Radiological findings. Flair images (A1) and Axial contrast-enhanced T1-weighted (A2) showed punctate and curvilinear enhancing lesions "peppering" on pons and cerebellum, with a large one in $1.07 \mathrm{~cm}$ diameter located in the right cerebellar hemisphere (arrow). There was no parotid malignancy observed at that time (D). With pulse therapy of intravenous methylprednisolone and following oral prednisolone, subsequent MRI showed the lesions decreased both in size and amount (B1, B2). When the dosage of prednisolone was tapered to 20 mg two months later, MRI showed recurring lesions (C1, C2). An enhancing nodule of $1.8 \mathrm{~cm}$ diameter was found in right masseter muscle (arrow) (E). After the resection of parotid malignancy $(F)$, with adjuvant radiotherapy, PCGE lesions disappeared on MRI (G) 
CLIPPERS was considered. Pulse therapy with methylprednisolone at $1 \mathrm{~g}$ per day was given for 5 consecutive days, followed by $60 \mathrm{mg}$ of oral prednisolone therapy (1 $\mathrm{mg} / \mathrm{kg}$ body weight) per day, slowly tapering to $20 \mathrm{mg}$. The clinical symptoms improved significantly, and MRI showed a decrease in the number and size of punctate and curvilinear gadolinium-enhancing (PCGE) lesions in the cerebellum and pons (Fig. 1. B1, B2). Two months later, when the daily dosage of oral prednisolone was reduced to $20 \mathrm{mg}$, the patient complained of recurring gait disturbance. Brain MRI revealed an increased number of PCGE lesions (Fig. 1. C1, C2). The clinical symptoms gradually resolved when the daily dose of oral prednisolone was increased to $50 \mathrm{mg}$. Azathioprine was added, and there was no recurrence, but the patient had a slight unsteady gait during follow-up.

Seven months later, MRI detected an enhancing nodule in the right masseter muscle (Fig. 1. E). The biopsy demonstrated parotid carcinoma (Fig. 2). After resection of the parotid carcinoma and subsequent radiotherapy, with daily dosages of $10 \mathrm{mg}$ oral prednisolone and $50 \mathrm{mg}$ azathioprine, the residual symptoms associated with CLIPPERS disappeared. To date, the patient is free of recrudescence of CLIPPERS, and the PCGE lesions disappeared on follow-up MRI (Fig. 1. G). A serum paraneoplastic autoantibody panel including anti-Hu, anti-Yo, anti-Ri, anti-CV2, anti-Ma1, anti-amphiphysin and anti-Tr was negative.

\section{Discussion and conclusions}

CLIPPERS is a chronic lymphocyte inflammation disorder predominantly infiltrating the pons and cerebellum. Our patient's clinical symptoms, histopathological characteristics, responses to prednisolone therapy, and MRI findings except for a large mass $(>3 \mathrm{~mm}$ in diameter) in cerebellum were consistent with the diagnostic criteria of CLIPPERS proposed by Tobin et al. [5].
Previously the diagnostic criterion of CLIPPERS according to brain MRI features, gadolinium enhancing nodules scattered in the pons and cerebellum were less than $3 \mathrm{~mm}$ in diameter; however, Taieb and his colleagues further evaluated the diagnostic criterion and suggested that nodular enhancement ( $>3 \mathrm{~mm}$ in diameter) can be included in the diagnostic criteria because the previous criterion lacked sensitivity and specificity [6]. During prolonged follow-up, the authors found that patients who initially didn't meet the diagnostic criteria of CLIPPERS due to nodular gadolinium enhancing ( $>3$ $\mathrm{mm}$ ), later met the diagnostic criteria of definite CLIPPE RS and probable CLIPPERS because of their clinical course, neuroimaging appearance and pathological findings [6]. In the reply letter by Tobin et al. to Taieb and coworkers [7], he agreed with the suggestion that enhancement lesions $>3 \mathrm{~mm}$ should not completely be ruled out, and required a further brain biopsy in the absence of alternative diagnosis in noninvasive investigations.

CLIPPERS is mediated by an autoimmune process without specific antibodies, which suggests it might not be a distinct nosological entity but a diagnosis that overlaps with other diseases. Paraneoplastic neurological syndromes (PNS) are inflammatory disorder predominantly mediated by $\mathrm{T}$ cells, and immune therapy lacks efficacy which is similar with CLIPPERS when steroids are weaned [8]. Specific antibodies have not been detected in CLIPPERS and many onconeural antibodies of PNS are unknot identified as well [8]. Many cases initially presented with clinical and radiological features of CLIPPERS, and then lymphoma is diagnosed in followup $[9,10]$. In addition to lymphoma, histiocytic sarcoma with an initial manifestation of CLIPPERS was reported as well [11]. CLIPPERS, a pre-stage of malignancy, may represent a compensatory and temporary host immune response, however, when the response becomes too weak, the
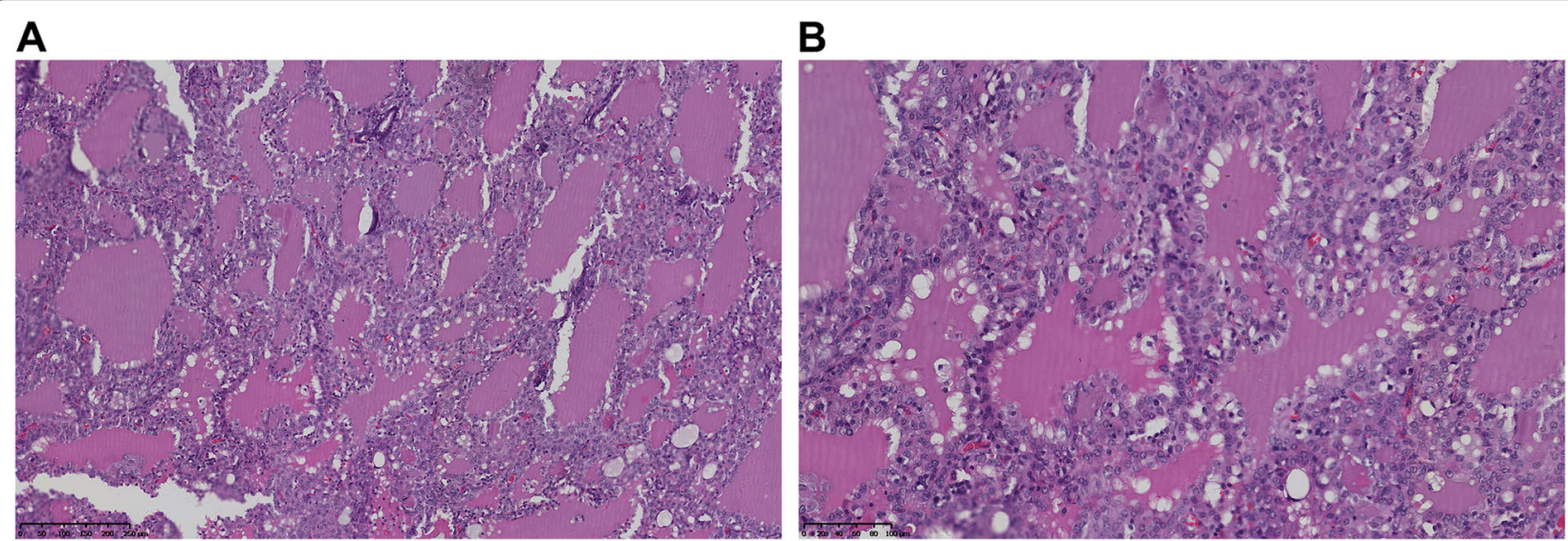

Fig. 2 The pathology of the right parotid biopsy. Tumor forms follicles, which contain eosinophilic secretory material, resemble to thyroid follicles (haematoxylin and eosin stain). $(\mathbf{a} ; \times 100, \mathbf{b} ; \times 200)$ 
lymphoma, histiocytic sarcoma might emerge [11, 12]. In addition, a similar mechanism might be applied to other malignancies. To the best of our knowledge, the patient we reported was the first case of CLIPPERS with an associated parotid carcinoma. Of note, after removal of parotid carcinoma, clinical symptoms and the PCGE lesions on MRI disappeared without relapse during long-term follow-up. Although common PNS antibodies were not found in our patient, this might be due to the fact that the testing was performed after the therapy of carcinoma and corticosteroid treatment, or a specific antibody associated with CLIPPERS in parotid carcinoma has not been identified.

There is a reported case of CLIPPERS where whole body gallium scan showed abnormal uptake in the parotid, and biopsy revealed chronic lymphocytic sialadenitis [13] . Noteworthily, a benign lesion in parotid might progress into malignancy. A reported case with a fullness at the angle of the right jaw, and the histopathological findings indicated sialadenitis. Two years later the patient complained of sudden painful enlargement of her right face, and a second biopsy demonstrated parotid acinic cell carcinoma with acute parotitis [14]. Therefore, long term follow-up might be needed to detect the progression of a benign lesion in the parotid even though the risk of missing a malignancy is small.

Whether CLIPPERS is an inflammatory disease or an overlapping syndrome with other diseases remains unknown. With an increasing number of cases reported in recent years, it is conceivable that CLIPPERS might be a pre-stage or unique presentation of other welldetermined diseases, such as lymphoma [10, 15], hemophagocytic syndrome [11], neuromyelitis optica spectrum disorders or other diseases [16]. Noteworthily, in the cases aforementioned, the diagnosis of CLIPPERS took a long duration (several months to 10 years), therein, diagnosis of CLIPPERS needs a long period of observation and monitoring. When patients are less responsive to corticosteroid therapy, it is suggested to re-evaluate the CLIPPERS criteria even though definite CLIPPERS was considered initially because it might suggest that the disease is in development and the underlying cause might be detected [6].

We would like to acknowledge some limitation in our report. This case is consistent with CLIPPERS according to the patient's clinical manifestation, radiological features and histopathological characteristics, but staining of antibodies such as glial fibrillar acidic protein astrocytopathy may help make a thorough differential of other diseases.

In conclusion, our case demonstrated that CLIPPERS might be a premalignant state, and systemic tumor screening is recommended, especially of the parotid gland. In addition, long-term follow-up is required in cases where some tumors are difficult to detect at the early stage.

\section{Abbreviations}

CLIPPERS: Chronic lymphocytic inflammation with pontine perivascular enhancement responsive to steroids; PNS: Paraneoplastic neurological syndromes; CSF: Cerebrospinal fluid; PCGE: Punctate and curvilinear gadolinium-enhancing

\section{Supplementary Information}

The online version contains supplementary material available at https://doi. org/10.1186/s12883-021-02135-6.

\section{Additional file 1: Figure S1. The pathology of cerebellum biopsy}

The Nanozoomer 2.0 HT series (Hamamatsu, Japan) was used, which is a system that converts glass slides into digital slides using the time delay integration (TDI) line scanning. A single slide was scanned at a resolution of 1.9 billion pixels in $1 \mathrm{~min} 40 \mathrm{~s}$. The measured resolution at which an image was acquired is $300 \mathrm{dpi}$. Neuropathology showed perivascular and parenchyma infiltration (haematoxylin and eosin stain) $(A ; \times 100)$. CD3positive $T$ lymphocytes infiltrates predominantly $(B \times 100)$ with some CD20-positive B lymphocytes $(C ; \times 100)$. CD4-positive T cells $(D ; \times 400)$. The CD8-positive cells are less than $50 \%$ of CD3-positive cells $\left(E_{;} \times 400\right)$. CD20-positive B cells $(F ; \times 400)$.

\section{Acknowledgements \\ We would like to thank the Department of Oral Pathology, School of Stomatology, West China hospital for the technical support.}

\section{Authors' contributions}

Y.D: Acquired data and drafted the manuscript. S. Z, M.L: Acquired data and revised the manuscript for intellectual content. B. Z, and B.W: Revised the manuscript for intellectual content. All authors read and approved the manuscript.

\section{Funding}

This work was supported by grants from National Natural Science Foundation of China (Grant No. 81974208). The funder contributed to the acquirement of the relevant data and revision of the manuscript.

\section{Availability of data and materials}

All data generated or analysed during this study are included in this published article [and its supplementary information files].

\section{Declarations}

Ethics approval and consent to participate Not applicable.

\section{Consent for publication}

Written informed consent was obtained from the patient for publication of this case report and any accompanying images. A copy of the written consent is available for review by the Editor of this journal.

\section{Competing interests}

The authors declare that they have no competing interests.

\section{Author details}

${ }^{1}$ Department of Neurology, West China Hospital, Sichuan University, Chengdu, Sichuan, China. ${ }^{2}$ Department of Pathology, West China Hospital, Sichuan University, Chengdu, Sichuan, China.

Received: 3 October 2020 Accepted: 2 March 2021

Published online: 10 March 2021

\section{References}

1. Pittock SJ, Debruyne J, Krecke KN, Giannini C, van den Ameele J, De Herdt V, McKeon A, Fealey RD, Weinshenker BG, Aksamit AJ, Krueger BR, Shuster EA, Keegan BM. Chronic lymphocytic inflammation with pontine perivascular enhancement responsive to steroids (CLIPPERS). Brain. 2010; 133(9):2626-34.

2. Zalewski NL, Tobin WO. Clippers. Curr Neurol Neurosci Rep. 2017;17(9):65.

3. Nakamura R, Ueno Y, Ando J, Matsuda H, Masuda A, liduka K, Shingai N, Takanashi M, Yokoyama K, Komatsu N, Hattori N. Clinical and radiological 
CLIPPERS features after complete remission of peripheral T-cell lymphoma not otherwise specified. J Neurol Sci. 2016;364:6-8.

4. Taieb G, Renard D, Joujoux JM, Labauge P. Cutaneous lesions in a CLIPPERS patient: further confusion between CLIPPERS and grade I lymphomatoid granulomatosis. J Cutan Pathol. 2014;41 (9):759-60.

5. Tobin WO, Guo Y, Krecke KN, Parisi JE, Lucchinetti CF, Pittock SJ, Mandrekar J, Dubey D, Debruyne J, Keegan BM. Diagnostic criteria for chronic lymphocytic inflammation with pontine perivascular enhancement responsive to steroids (CLIPPERS). Brain. 2017;140(9):2415-25.

6. Taieb G, Mulero P, Psimaras D, van Oosten BW, Seebach JD, Marignier $R$, Pico F, Rigau V, Ueno Y, Duflos C, Fominykh V, Guiraud V, Lebrun-Frénay C, Camdessanché JP, Kerschen P, Ahle G, Téllez N, Rovira A, Hoang-Xuan K, Pelletier J, Labauge P. CLIPPERS and its mimics: evaluation of new criteria for the diagnosis of CLIPPERS. J Neurol Neurosurg Psychiatry. 2019;90(9): 1027-38.

7. Tobin WO, Guo Y, Krecke KN, Keegan BM. Reply: a case of CLIPPERS challenging the new diagnostic criteria. Brain. 2018;141(2):e13.

8. Braik T, Evans AT, Telfer M, McDunn S. Paraneoplastic neurological syndromes: unusual presentations of cancer. A practical review. Am J Med Sci. 2010;340(4):301-8.

9. Taieb G, Uro-Coste E, Clanet M, Lassmann H, Benouaich-Amiel A, Laurent C, Delisle MB, Labauge P, Brassat D. A central nervous system B-cell lymphoma arising two years after initial diagnosis of CLIPPERS. J Neurol Sci. 2014; 344(1-2):224-6.

10. De Graaff HJ, Wattjes MP, Rozemuller-Kwakkel AJ, Petzold A, Killestein J. Fatal B-cell lymphoma following chronic lymphocytic inflammation with pontine perivascular enhancement responsive to steroids. JAMA Neurol. 2013;70(7):915-8.

11. Li Z, Jiang Z, Ouyang S, Li Y, Yang H. CLIPPERS, a syndrome of lymphohistiocytic disorders. Mult Scler Relat Disord. 2020;42:102063.

12. Taieb G, Renard D, Labauge P. Should CLIPPERS be considered a Prelymphoma state or a new inflammatory disease? JAMA Neurol. 2013; 70(9):1200-1.

13. Simon NG, Parratt JD, Barnett MH, Buckland ME, Gupta R, Hayes MW, Masters LT, Reddel SW. Expanding the clinical, radiological and neuropathological phenotype of chronic lymphocytic inflammation with pontine perivascular enhancement responsive to steroids (CLIPPERS). J Neurol Neurosurg Psychiatry. 2012;83(1):15-22.

14. Shocket E, Manheimer LH, Benson J, Lubin J. Calcified parotid carcinoma masquerading as benign calculus with acute parotitis. South Med J. 1982; 75(10):1273-4

15. Liu XH, Jin F, Zhang M, Liu MX, Wang T, Pan BJ, Zhang L. Peripheral T cell lymphoma after chronic lymphocytic inflammation with pontine perivascular enhancement responsive to steroids (CLIPPERS): a case report. BMC Neurol. 2019;19(1):266

16. Symmonds M, Waters PJ, Küker W, Leite MI, Schulz UG. Anti-MOG antibodies with longitudinally extensive transverse myelitis preceded by CLIPPERS. Neurology. 2015;84(11):1177-9.

\section{Publisher's Note}

Springer Nature remains neutral with regard to jurisdictional claims in published maps and institutional affiliations.

\section{Ready to submit your research? Choose BMC and benefit from:}

- fast, convenient online submission

- thorough peer review by experienced researchers in your field

- rapid publication on acceptance

- support for research data, including large and complex data types

- gold Open Access which fosters wider collaboration and increased citations

- maximum visibility for your research: over $100 \mathrm{M}$ website views per year

At $\mathrm{BMC}$, research is always in progress.

Learn more biomedcentral.com/submissions 